УДК 538. 951

\title{
ДЕФОРМАЦИЯ РАЗРУШЕНИЯ ПОЛИМЕРНЫХ КОМПОЗИЦИОННЫХ МАТЕРИАЛОВ ПОСЛЕ ВЫДЕРЖКИ В ДИСТИЛЛИРОВАННОЙ ВОДЕ И 10\%-М РАСТВОРЕ ГИДРОКСИДА НАТРИЯ
}

Акаева Маднат Магомедовна

к.т.н., доцент

Солсаева Товрат Селимхаевна Джамбулатова Хадижат Исламовна

ФГБОУ ВО «Чеченский государственный университет»

\begin{abstract}
Аннотация: в работе измерена концентрационная зависимость деформации разрушения по Шарпи $\varepsilon_{\mathrm{p}}$ полимер-полимерных смесей полибутилентерефталат - полиэтилен после выдержки в жидких агрессивных средах. Содержание образцов в жидкой среде максимально приближенным к естественным условиям эксплуатации полимерного материала. Показано, что значительное усиление матрицы композиционного материала, введение неполярного полиэтилена высокой плотности в полибутилентерефталата способствует повышению стойкости к агрессивным средам.
\end{abstract}

Ключевые слова: полибутилентерефталат, полиэтилен, агрессивная среда, композиционный материал, механические свойства.

Abstract: in this work, the concentration dependence of the Sharpie fracture strain $\varepsilon_{\mathrm{p}}$ of polymer-polymer mixtures of polybutylene terephthalate - polyethylene after exposure to liquid aggressive media was measured. The content of samples in a liquid medium is as close as possible to the natural operating conditions of the polymer material. It is shown that a significant strengthening of the composite material matrix, the introduction of non-polar high-density polyethylene into the polybutylene terephthalate matrix contributes to increased resistance to aggressive media.

Key words: polybutylene terephalate, polyethylene, aggressive sphere, composite material, mechanic features.

В настоящее время получение композиционных материалов типа 
«полимер - полимер», обладающих хорошими механическими и технологическими свойствами и высокой химической стойкостью, является весьма актуальной задачей [1, с. 6, 2, с. 37].].

В работе были исследованы КМ на основе ПБТ в зависимости от содержания полиэтилена в концентрациях 2,5\%; 5\%; 10\%; 20\%; 30\%, приготовленные экструзией. Для стабилизации физико-химических свойств смеси применялись стабилизирующие добавки irganox-B 225.

Механизм влияния химически активных сред на полимерные материалы значительно отличается от физически активных сред. В зависимости от времени и условий контакта химически активные среды могут вызвать необратимые процессы изменений в химической и физической структуре полимеров. Известно, что гетероцепные полимеры неустойчивы к действию воды, водных растворов кислот и оснований [3, с. 173]. Следует отметить, что реакции гидролиза в дистиллированной воде протекают очень медленно и для их ускорения добавляют кислоты и основания в различных концентрациях. Поэтому изменение физико-химических свойств полимеров при контакте с такими средами, даже для ненагруженных материалов, считается максимально приближенным к естественным условиям эксплуатации.

Динамика изменения механических свойств полимерных материалов в агрессивных средах не всегда последовательна и монотонна. Случаи скачкообразного изменения конкретных параметров в процессе экспонирования полимеров, особенно в ненапряженном состоянии, в агрессивных средах довольно часты [1, с. 8,3 , с. 23$]$.

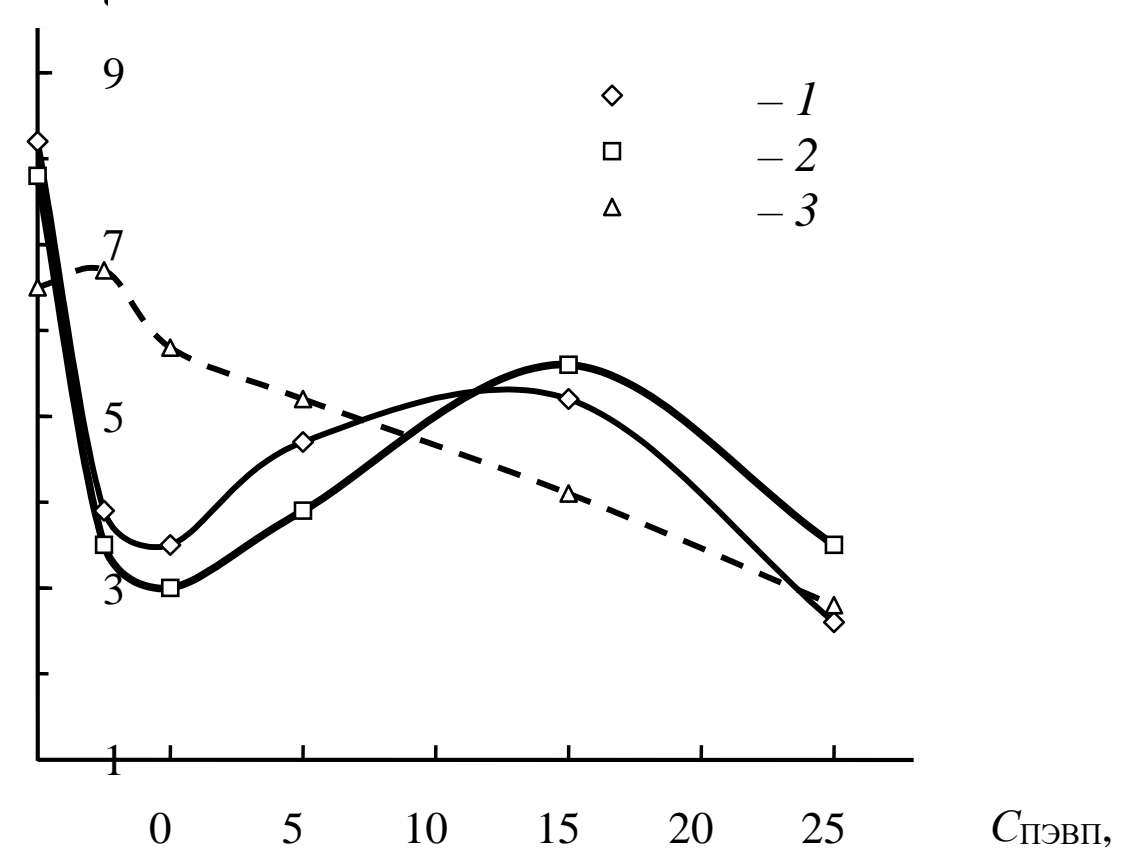

Рис. 1. Концентрационная зависимость деформации разрушения в испытаниях по Шарпи єр композиций ПБТ + ПЭВП через 24 часа выдержки в дистиллированной воде (1) и 10\%-м растворе $\mathrm{NaOH}$ (2). (3) - исходные образцы композиций 


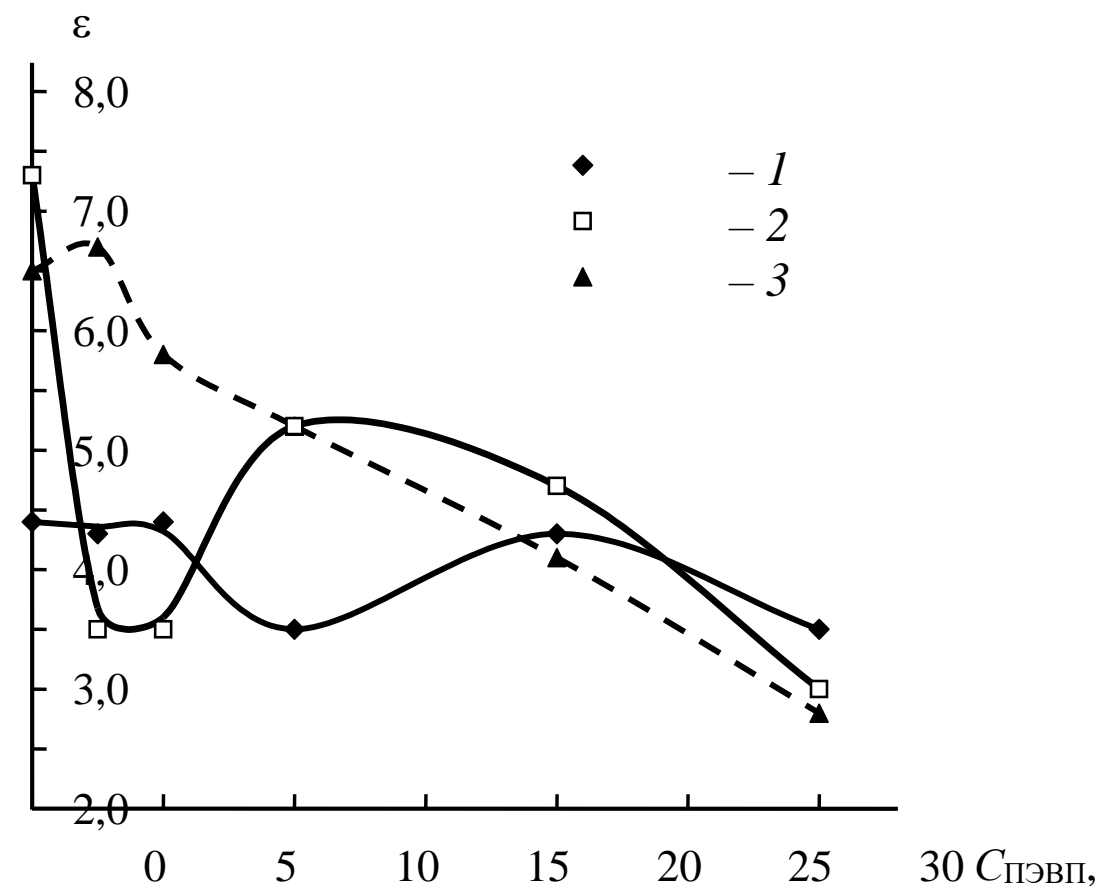

\section{Рис. 2. Концентрационная зависимость деформации разрушения в испытаниях по Шарпи $\varepsilon_{\mathrm{p}}$ композиций ПБТ + ПЭВП через 48 часов выдержки в дистиллированной воде (1) и 10\%-м растворе $\mathrm{NaOH}$ (2). (3) - исходные образцы композиций}

Изучение поведения ПБТ и ПКМ ПБТ-ПЭ в 10\%-ном водном растворе $\mathrm{NaOH}$ представлялось важным потому, что водные растворы щелочей оказывают значительное воздействие на матрицу компонентов ПКМ, и, в первую очередь, на кинетику гидролитических процессов, которые отражаются на конкретных механических свойствах [2, с. 101].

Для деформационных свойств (рис. 1, 2) характерно снижение деформации разрушения $\varepsilon_{\mathrm{p}}$ для ПКМ ПБТ-ПЭ вплоть до 10-\%-ного содержания ПЭ с последующей стабилизацией при более высоком содержании ПЭ в ПКМ. Зависимость $\varepsilon_{\mathrm{p}}$ от времени экспонирования в определенной мере моделирует и концентрационную: т.е. ход кривых $\varepsilon_{\mathrm{p}}=\mathrm{f}([\Pi Э])$ во многом однозначно отражается на зависимостях $\varepsilon_{\mathrm{p}}=\mathrm{f}\left(t_{\text {эксп }}\right)$.

Таким образом, в результате проведенных исследований получены полимерные композиции на основе полибутилентерефталата, модифицированного полиэтиленом высокой плотности. Содержание полиэтилена в композициях варьировалось до $30 \%$. В ряде случаев наблюдалось усиление матрицы композиции в процессе экспонирования. Эти наблюдения можно отнести к проявлению квазипроцессов структурирования и 
кратковременного упрочнения, характерных для поведения термопластов в окислительной среде.

\section{Список литературы}

1. Акаева М.М., Машуков Н.И. // Пластические массы. - 2008. - №11. C. 5-8.

2. Зуев Ю. С. Разрушение полимеров под действием агрессивных сред 2 е изд., перер. и доп. - М.: Химия. - 1972. - 230 с.

3. Воробьева Г.Я. Химическая стойкость полимерных материалов, М.: Химия. $-1981 .-293$ с.

(C) М.М. Акаева, Т.С. Солсаева, Х.И. Джамбулатова, 2020 